\title{
Thoracic Aortic Dissecting Aneurysm Presenting with Stroke, Disseminated Intravascular Coagulopathy, and Gastrointestinal Hemorrhage
}

\author{
Soraya Moghadam MD, Yoshitsugu Nakamura MD, Mackenzie Quantz MD, Raymond Kao, MD
}

\section{About the Authors \\ Soraya Moghadam is an internist/nephrologist with the Canadian Forces Health Services and is based in Ottawa; Raymond Kao is with the Canadian Forces Health Services and staff intensivist; Yoshitsugu Nakamura is a cardiac surgery fellow; and Mackenzie Quantz is a staff cardiac surgeon - all at London Health Sciences Centre, London, ON. Correspondence may be directed to rkao3@uwo.ca}

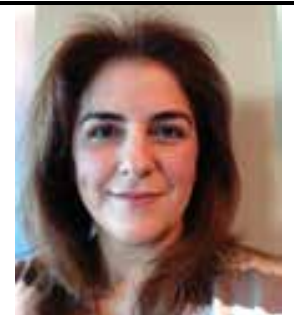

Moghadam

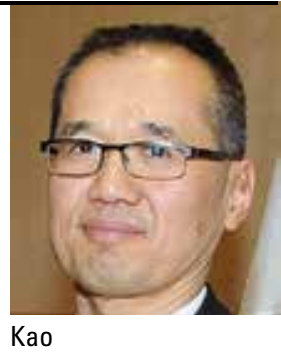

\section{Summary}

Acute ischemic stroke secondary to vessel occlusion from an aneurismal dissection is an uncommon presentation. Disseminated intravascular coagulation (DIC) can present as a consequence of aortic dissection, although this is also rare. In some cases, the laboratory diagnosis of DIC uncovers a vascular abnormality or bleeding diathesis. This article describes a patient presenting with three sequential complications of a dissecting thoracic aortic aneurysm: ischemic stroke, upper gastrointestinal bleeding, and consumptive coagulopathy.

\section{Résumé}

L'accident vasculaire cérébral (AVC) ischémique aigu secondaire à l'occlusion vasculaire découlant d'une dissection anévrismale est rare. La coagulation intravasculaire disséminée (CIVD) peut se produire à la suite de la dissection aortique, quoique cela soit rare également. Dans certains cas, le diagnostic de CIVD en laboratoire dévoile une anomalie vasculaire ou un phénomène de diathèse sanguine. Nous présentons le cas d'une femme de 73 ans qui a subi trois complications successives de la rupture d'un anévrisme de l'aorte thoracique : un AVC ischémique, un saignement digestif haut et une coagulopathie de consommation. 


\section{Case}

A 73-year-old woman experienced shortness of breath and an inability to walk while at church. She then had a sudden decrease in level of consciousness and was brought to the local hospital. Her medical history included hypertension, osteoarthritis, and a history of smoking 20 packs of cigarettes a year. Her medications on presentation were enalapril, aspirin, and meloxicam. Her decreased level of consciousness improved with intravenous fluid resuscitation. Then she complained of headache and leftsided weakness. Her heart rate was 68 beats per minute (BPM) and regular, blood pressure was $89 / 45$ lying, and temperature was $37.8^{\circ} \mathrm{C}$. A computed tomography (CT) head followed by angiography was completely normal. A CT chest showed a Type A aortic dissecting aneurysm extending downwards, from the aortic root to the mid-abdominal aorta and upwards into the right common carotid artery, which was occluded proximately (Figure 1).

She was transferred to the London Health Sciences Centre, Cardiac Surgery Recovery Unit (CSRU). En route, the patient had a gastrointestinal hemorrhage with melena and bright red blood per rectum. Upon arrival, her heart rate was 76 BPM, blood pressure was 115/50 lying, respiratory rate was 20 breaths per minute, and temperature was $32.3^{\circ} \mathrm{C}$. Fluid resuscitation was continued and a nasogastric tube was inserted, resulting in drainage of a significant amount of bright red blood. Initial laboratory results revealed a hemoglobin of $136 \mathrm{~g} / \mathrm{L}$ (subsequently $99 \mathrm{~g} / \mathrm{L}$ ), white blood cell count of $22.2 \times 10^{9} / \mathrm{L}$, platelets decreased at less than $20 \times 10^{9} / \mathrm{L}$ with some clumping, international normalized ratio (INR) 2.0, partial thromboplastin time (PTT) 59, fibrinogen $0.41 \mathrm{~g} / \mathrm{L}$, lactate $1.0 \mathrm{mmol} / \mathrm{L}$, alanine aminotransferase (ALT) $37 \mathrm{U} / \mathrm{L}$, aspartate aminotransferase (AST) $52 \mathrm{U} / \mathrm{L}$, sodium $142 \mathrm{mmol} / \mathrm{L}$, potassium $3.5 \mathrm{mmol} / \mathrm{L}$, chloride $119 \mathrm{mmol} / \mathrm{L}$, bicarbonate $13 \mathrm{mmol} / \mathrm{L}$, urea $6.1 \mathrm{mmol} / \mathrm{L}$ and creatinine $48 \mu \mathrm{mol} / \mathrm{L}$. She was aggressively warmed and resuscitated throughout the night with one unit pooled platelets and two units pooled cryoprecipitate, four units of fresh frozen plasma, and two units of packed red blood cells. The gastroenterology service was not consulted because she stabilized by early morning.

The cardiac surgeon and intensive care physician felt this stabilization provided a window of opportunity for operative repair of her Type A aortic dissection. Prior to the operation her hemoglobin was $121 \mathrm{~g} / \mathrm{L}$, white blood cell count $7.8 \mathrm{x}$ $10^{9} / \mathrm{L}$, platelets $129 \times 10^{9} / \mathrm{L}$, INR 1.2 , PTT 30 , fibrinogen 1.91 $\mathrm{g} / \mathrm{L}$, lactate $1.1 \mathrm{mmol} / \mathrm{L}$, ALT $40 \mathrm{U} / \mathrm{L}$, AST $61 \mathrm{U} / \mathrm{L}$, sodium $145 \mathrm{mmol} / \mathrm{L}$, potassium $3.4 \mathrm{mmol} / \mathrm{L}$, chloride $114 \mathrm{mmol} / \mathrm{L}$, bicarbonate $19 \mathrm{mmol} / \mathrm{L}$, urea $7.6 \mathrm{mmol} / \mathrm{L}$ and creatinine 65 $\mu \mathrm{mol} / \mathrm{L}$. At surgery, an intima tear in the posterior middle portion of the ascending aorta was noted, and the hemi-arch was

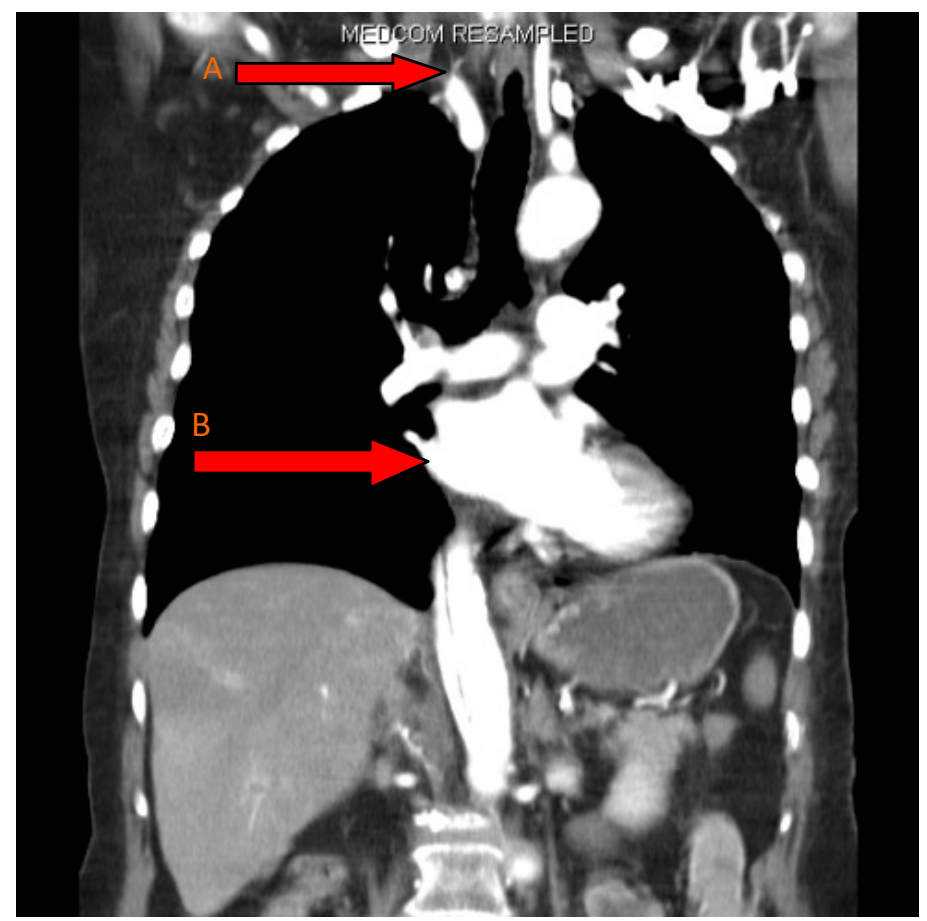

Figure 1. Computed tomography chest coronal-sectional view of the right carotid artery occlusion (Arrow A) and the aortic thoraco-abdominal dissection. (Arrow B).

replaced with a 29-mm Gel weave conduit. The root of the aortic valve was frail and required repair with BioGlue. She tolerated the surgery well and there was no post-operative bleeding. Her platelet count dropped progressively over the next 48 hours to a nadir of $26 \times 10^{9} / \mathrm{L}$; her INR and PTT were normal, and her fibrinogen level was $>1 \mathrm{~g} / \mathrm{L}$. A follow-up magnetic resonance imaging (MRI) and magnetic resonance angiogram (MRA) of the head and neck revealed multiple small acute infarcts in the right cerebral hemisphere; both carotid vessel bifurcations had normal appearances with no evidence of carotid or vertebral artery dissection. The carotid occlusion noted earlier on CT scan was now patent. She continued to do well with resolution of her disseminated intravascular coagulation (DIC). She was transferred to the ward, and later to her home hospital, for continuing physiotherapy and rehabilitation of her mild left-sided motor deficit. Her medications on transfer were metoprolol $50 \mathrm{mg}$ twice daily and lansoprazole $20 \mathrm{mg}$ once daily.

\section{Discussion}

Thoracic aortic aneurysms can cause cerebral infarction by dissecting to the carotid vessels, leading to perfusion deficits from the dissection and from branch vessel occlusion. ${ }^{1,2}$ The dissection can also extend inferiorly, involving the descending aorta and the superior mesentery artery, leading to bowel infarction and gastrointestinal bleeding. ${ }^{3}$ In uncomplicated arterial aneurysms and in spontaneous aortic dissection, the 
extensive thrombus formation can trigger DIC, with a reported incidence of $4 \% .{ }^{4}$ In this report we describe a patient who presented with all three complications - stroke, DIC, and gastroenterological hemorrhage, resulting from Type A aortic dissection.

In a post-mortem study in 1819, Laennec described two significant factors that can cause aortic dissection: 1) a predisposing structural weakness of the aortic wall and 2) an initiating event. ${ }^{5}$ This is usually in the intima, but based on autopsy studies, it occurs in the media in $4 \%$ of the cases. ${ }^{6}$ The common causes of aortic structural weaknesses are arterial hypertension, aortic dilatation, bicuspid aortic valve, coarctation of the aorta, aortic arch hypoplasia, Marfan's syndrome, pregnancy, and aging. The initiating event can be a sudden increase in either systemic vascular resistance or systemic vascular pressure, or trauma to the aorta. ${ }^{5}$ However, the understanding of aortic aneurysm formation and dissection has evolved since Laennec, and we now know the genetic implications of extracellular matrix proteins, smooth muscle cells, and growth factors as they relate to aortic wall homeostasis. These predeterminants are also influenced by smoking, hypertension, and atherosclerosis, which result in an inflammatory response coupled with an accelerated proteolytic cascade that disrupts elastin and collagen in the arterial wall. ${ }^{7}$ Our patient had hypertension and smoked a half-pack of cigarettes per day for 40 years; these factors may have contributed to her aortic structural weakness. We believe a sudden increase in her systemic vascular pressure may have led to her aortic dissection.

DIC is a life-threatening syndrome associated with several clinical conditions, including sepsis, cancer, severe burns, prosthetic devices, liver disease, trauma-related injuries, obstetric complications, transplant rejection, transfusion reactions, and vascular abnormalities. The association of DIC with aortic aneurysm was first reported by Fine and colleagues in $1967 .{ }^{8}$ This association is clinically relevant from two perspectives: first, it represents a source of perioperative complication in a major surgical procedure; and second, it provides a lesson to consider vascular abnormalities in the differential diagnosis of DIC, since its early detection can potentially reduce significant morbidity and mortality.

Acute ischemic stroke secondary to vessel occlusion from an aneurismal dissection is an uncommon presentation, ${ }^{3}$ but it has been described secondary to DIC. ${ }^{9}$ In a case series of 272 patients with aortic dissection, one patient presented with a stroke, ${ }^{1}$ and seven patients suffered preoperative stroke. ${ }^{2}$ Only one reported DIC case resulted in brain and spinal cord infarction. ${ }^{10}$ Aortic dissections can lead to other vascular structural complications, such as superior mesenteric artery (SMA) dissection with bowel infarction, and lower gastrointestinal bleed: our patient's SMA was not dissected and continued to be fed by the true lumen of the aorta. Our patient's upper gastrointestinal bleed appeared to be associated with her consumptive coagulopathy from the aortic dissection. This bleeding could have been further exacerbated by the non-steroidal anti-inflammatory drug use and the hypothermia developed during transport to the Cardiac Surgery Recovery Unit.

\section{Conclusion}

Our case illustrates that one should consider the possibility of a dissecting aortic aneurysm in any patient presenting with neurological symptoms and acute gastrointestinal bleed, with or without DIC. DIC induced from an aneurysm is a rare presentation that is most frequently diagnosed perioperatively; however, it can be a useful clue to the diagnosis of a vascular abnormality. The preoperative incidence of DIC associated with an aneurismal dissection is estimated to be $3-4 \%{ }^{7}$ and is managed in a similar fashion, that is, by treating the underlying disorder.

\section{References}

1. Sadhwani D, O’Mara K. Acute dissecting thoracic aneurysm presenting with stroke, consumptive coagulopathy, and gastrointestinal hemorrhage. Emerg Med J 2001;17:631-5.

2. Fann JL, Sarris GE, Miller DC, et al. Surgical management of acute aortic dissection complicated by stroke. Circulation 1989;80(Suppl 3):1257-63.

3. Cambria RP, Brewster DC, Gertler J, et al. Vascular complications associated with spontaneous aortic dissection. J Vasc Surg 1988;7:199-209.

4. Fisher DJ, Yawn DH, Crawford ES. Preoperative disseminated intravascular coagulation associated with aortic aneurysms. A prospective study of 76 cases. Arch Surg 1983;118:1252-5.

5. Eagle KA, DeSanctis RW. Aortic dissection. In: O’Rourke R, McCall D, eds. Current problems in cardiology, Vol.14. Chicago: Year Book Medical Publishers, 1989:225-78.

6. Hirst AE, Johns VJ, Kime SW. Dissecting aneurysm of the aorta: a review of 505 cases. Medicine 1958;37:217-79.

7. Fernandez-Moure JS, Vykoukai D, Davies MG. Biology of aortic aneurysm and dissections. Methodist Debakey Cardiovasc J 2001;7:2-7.

8. Fine NL, Applebaum J, lguezabal A, et al. Multiple coagulation defects in association with dissecting aneurysm. Arch Intern Med 1967;119:522-6.

9. Urakami K, Adachi Y, Takahashi K, et al. Cerebral infarction due to disseminated intravascular coagulation with thromboexculsion for dissecting aortic aneurysm. Jpn J Psychiatry Neurol 1989;43:241-4.

10. Libman R, Wirkowski E, Alvir J, et al. Conditions that mimic stroke in the emergency department. Arch Neuro 1995;52:1119-22. 